\title{
The Meanings of "Imagine" Part II: Attitude and Action
}

\author{
(penultimate; final in Philosophy Compass 9(11), 791-802 [2014]; please cite final)
}

\section{Neil Van Leeuwen}

I clarified, in Part I, different senses of "imagine" and "imagination." Each has a constructive sense, an attitude sense, and an imagistic sense. ${ }^{1}$ I then asked a question concerning imaginings of any sort, like the dragon imagining you may have had in response to my prompt:

1. How do they arise?

In other words, what are the principles by which constructive imagining operates? The remainder of Part I partially answered this question through the Sensory Construction Thesis, the Belief Governance Thesis, and the Genre Truth Governance Thesis. Constructive imagination can largely be thought of as exploratory constraint satisfaction, where the constraints on a given episode of imagining are largely elements of reality-oriented cognition, like beliefs and perception.

But this view just makes our second question, which is targeted at attitude imaginings, all the more pressing, since an answer to this second question seems presupposed in the answer we just gave to the first question. Of attitude imaginings:

2. What are their typical characteristics viewed synchronically, including ones that separate them from related states, like belief and perception? ${ }^{2}$

And once we consider this question carefully, we'll be in a position to ask our third question, also focused on attitude imaginings:

3. What are their downstream consequences on emotion and action, especially pretense (or make-believe)?

So our foci for Part II are attitudes and action. But beyond just discussing various possible answers to 2 and 3, I want to give a sense of just how difficult these questions are. At the time of writing, there is no clear consensus answer to what differentiates imagining from belief. Nor is there a consensus about how imaginings are implicated in the generation of action. So I hope, above all, to convey a sense of the philosophical interest inherent in both questions.

\footnotetext{
${ }^{1}$ See Part I (2013) for further clarification.

${ }^{2}$ For reasons of space, the present Part will focus on the contrast between attitude imagining and belief. I do think, however, that the anti-symmetry claim I develop here can be extended (with modifications) to the relation between perception and imagery.
} 


\section{The Problem: What's the difference between believing and imagining?}

Recall that we're focused on attitudes, or what I call attitude imagining; that is, a cognitive attitude that has propositional content. Consider the following contrasts.

(1) Beth believes it will snow tomorrow.

(2) Ian imagines (fictionally) it will snow tomorrow.

(3) Alvin assumes for the sake of argument it will snow tomorrow.

(4) Heather hypothesizes it will snow tomorrow.

The dimension of variation here-aside from the agents themselves-is what we call attitude, as I pointed out in Part I. The contents of the mental states under consideration are all the same, as (we may presume) are the structures of the internal representations in which the contents are encoded. Only the attitudes are different.

Now focus on (1) and (2). Our task is to characterize the attitude referred to in (2), and doing that, at a minimum, will involve sufficiently and non-circularly distinguishing that attitude from the attitude referred to in (1). (And perhaps a theory that distinguishes (2) from (1) will be helpful for handling (3) and (4) also.) It turns out, however, that this is no small task. Neil Sinhababu (2013) puts the problem as well as anyone: "Believing that $p$, imagining that $p$, and assuming that $p$ are ways of representing that $\mathrm{p}$. What distinguishes believing from imagining and assuming?" Sinhababu goes on to argue that application of a norm of truth is neither necessary nor sufficient to turn an imagining into a belief. One might apply such a norm to some of her imaginings, trying only to imagine that for which there is some evidence of truth, without thereby making the imaginings into beliefs; and one might, out of adherence to pragmatism, refuse to apply such a norm to one's beliefs, without thereby making them any less beliefs. So if Sinhababu's argumentation is right, the question becomes even more pressing: what does distinguish belief from imagining?

Since answering this question is central to our present concern of understanding attitude imaginings generally, I'll discuss three approaches to it: the sentiment-based (or phenomenological) approach suggested by David Hume, the teleological approach of David Velleman, and the inferentialist approach suggested by Sinhababu and others. It will turn out that an inferentialist view might just work, but not quite in the form Sinhababu presents it; if, however, we modify Sinhababu's view in the right way, we'll have a viable candidate answer. In any case, we should keep in mind that this is still an open question, on which more work should be done. ${ }^{3}$

\footnotetext{
3 There are approaches to this problem that I don't have space here to discuss fully. McGinn (2004, pp. 128 ff.), for example, talks about "cognitive imagination" and claims "imagining that $p$ is an action, while believing that $\mathrm{p}$ is not" (p. 131). But I don't think that this claim can address our problem of distinguishing belief from imagining as handily as McGinn might think, since saying that imagining is an action seems to conflate attitude imagining with constructive imagining. O'Shaughnessy (2000, ch. 11-13) also presents a taxonomy and analysis of imagination that is well worth considering.
} 
We should also ask why the problem here may be so tricky, and an answer to this question is encoded in the phrase "make believe": that phrase only makes sense if the imaginings underlying pretense share many of the characteristics of beliefs. And if imaginings share many of the characteristics of beliefs, it will be correspondingly trickier to distinguish the two attitudes. ${ }^{4}$

\section{Sentiment-Based: Hume's Approach \\ David Hume raises our very problem in the Enquiry:}

Wherein, therefore, consists the difference between such a fiction and belief? It lies not merely in any peculiar idea, which is annexed to such a conception as commands our assent, and which is wanting to every known fiction. For as the mind has authority over all its ideas, it could voluntarily annex this particular idea to any fiction, and consequently be able to believe whatever it pleases; contrary to what we find by daily experience. (p. 31)

"Fiction" here, I take it, means fictional imagining. ${ }^{5}$ Hume argues that no idea distinguishes such imagining from belief. That is, no internal constituent of the contents we take attitudes toward (or of the representations in which those contents are encoded) constitutes the difference between imagining and belief. Consider, for example, the idea of being true and how it plays out in these three attitudes:

(5) Frank believes it is snowing.

(6) Frank imagines it is snowing.

(7) Frank imagines it is true that it is snowing.

The attitude in (7) doesn't turn into the attitude in (5) just by representing the idea of truth. ${ }^{6}$ Hume tells us that the same goes for any idea: idea differences don't add up to attitude differences. Here's how his argument works.

1. One cannot believe just anything at will. [premise]

2. One can combine any ideas at will. [premise]

3. An idea $i$ that attends all beliefs distinguishes belief from imagining. [assumption with an eye to reductio]

4. A person can combine $i$ with any other idea at will. [from 2]

5. A person can believe anything at will. [from 3 and 4]

${ }^{4}$ That the two attitudes share characteristics is very much one of the points of the simulationist program for imaginings, advocated most notably in Currie and Ravenscroft (2002).

5 This can be seen in how he contrasts the term "fiction" with belief and in how he separates those attitude terms from "idea," which is a way of representing. One can have one or the other attitude to the same idea.

${ }^{6}$ Velleman (2000a) also makes this point. I think it is important, because people often try to explain belief in terms of what one "takes to be true," e.g., Schellenberg (forthcoming). But if the present point is correct, it's not clear how the phrase "takes to be true" could do the needed explaining. Of course, the phrase sounds right, but I think that's because "takes to be true" activates the antecedent concept of belief in the listener and thus is parsed like "believes to be true." But activating a concept is not explaining it. 
6. Contradiction. [from 5 and 1 ]

7. 3 is false. [from 3 through 6 ]

We saw above that thinking of contents under the idea they are true is not sufficient to make them believed, since one could just as well merely imagine they are true; Hume's conclusion simply generalizes the point to all ideas. But what does he think follows from this? "It follows, therefore, that the difference between fiction and belief lies in some sentiment or feeling, which is annexed to the latter, not to the former..."7 Belief is "vivid, lively, forcible, firm, steady." So Hume evidently thinks beliefs have some phenomenology that imaginings don't.

But does a sentiment or feeling really distinguish belief from imagining? It seems, on the contrary, imaginings can also fit Hume's description of the mooted belief sentiment. Someone obsessed with the show Sopranos might steadily and forcibly (or whatever) imagine being friends with Tony Soprano, without believing it. So it's hard to see that such a feeling is sufficient for belief. Furthermore, many beliefs don't feel forceful or vivid, like my belief that pens take ink. So it's hard to see that such a feeling is necessary. ${ }^{8}$

So our problem is still open, since it's not clear that Hume's phenomenology will solve it. But considering Hume allows progress in a different direction: we see two dimensions of similarity between belief and imagining. First, we discovered that any idea that can partake in belief can partake in imagining. Second, if a sentiment/feeling can't distinguish belief from imagining, that's because (at least to a great extent) similar sentiments/feelings can attend both.

\section{Teleology: Velleman's Approach}

David Velleman (2000a) takes a different tack. He argues that beliefs aim at truth. ${ }^{9}$ There is, he holds, a "spectrum" of ways this aim can be realized. At one end, the agent deliberately intends to accept only truths. At the other end, sub-personal mechanisms that form cognitive attitudes can be designed to yield true ones. Belief, as opposed to imagining, is "regulated, either by the subject's intentions or by some other mechanisms, in ways designed to ensure that it is true" (p. 254).

This theory faces a natural objection. Aren't many beliefs the product of truth-opposed processes, like self-deception? If so, how can they be said to aim at truth? Velleman has a response: he never said that the truth aim is the only influence on belief formation. He just said that aim at truth is, for every belief, one of the influences on its formation.

To clarify, let's draw a distinction:

An attitude strongly aims at truth iff only truth-tracking mechanisms form and revise it.

\footnotetext{
${ }^{7}$ p. 31. All references to the Enquiry are to the Hackett Second edition.

${ }^{8}$ See Stroud (1981, pp. 69 ff.) for more in-depth discussion of this exact issue.

${ }^{9}$ Note that Shah and Velleman (2005) depart from Velleman's (2000a) view in important ways. Nevertheless, I focus on Velleman (2000a) here for three reasons: the position in that piece is theoretically tempting; its refutation is instructive; and it has been influential.
} 
An attitude weakly aims at truth iff some truth-tracking mechanisms are among those that form and revise it. ${ }^{10}$

Velleman's use of "aims at truth" corresponds to the weak sense, so self-deception isn't a counterexample, since it seems that even in self-deception there is a teaspoon of evidence in the agent's mind that coheres with the self-deceptive belief. ${ }^{11}$

But now Velleman has another problem: some imaginings also weakly aim at truth. Recall from Part I that constructive imagining largely uses inferential processes that govern thought about reality. So a given imagining will likely have some mechanisms aimed at truth in its etiology. Thus, to say beliefs strongly aim at truth is false. To say beliefs weakly aim at truth doesn't distinguish belief from imagining, since many imaginings weakly aim at truth too. ${ }^{12}$

Velleman's approach, it seems, won't work. But though his attempt fails, it boosts the lesson we've been working on. Critiquing Velleman reveals more support for the view that imaginings share many of the characteristics of belief: many (if not most) imaginings appear to have a weak truth aim (in the relevant sense) as well. ${ }^{13}$

\section{Inferential Approaches: Sinhababu and Others}

We've seen that prominent sentiment-based and truth-aim approaches have difficulties. Another approach is to say beliefs and imaginings have different inferential properties. Sinhababu, for example, suggests that “...beliefs stand in particular inferential relations to one another-if one believes that $p$ and believes that if $\mathrm{p}$ then $\mathrm{q}$, and reflects on these propositions, one typically forms the belief that q" (p. 160).

Though it sounds promising, this version of the inferential approach won't work. Let's consider the issue formally. Let CA___ be any cognitive attitude. Consider Schema I (I for inference):

If one has $\mathrm{CA}$ that $p$ and $\mathrm{CA}$ these, one typically forms $\mathrm{CA}$ that if $p$ then $q$, and reflects on that $q$.

This schema makes conformity to modus ponens a partial characterization of a cognitive attitude. Sinhababu seems to hold that this schema characterizes belief, as opposed to imagining. But that's not right, as he admits: "if I imagine that my house is on fire, and imagine that if my house is on fire I'm in danger, I'll be imagining that

\footnotetext{
10 The phrase "aim at truth" is used in a number of ways in the literature. I don't wish to address all of them. I introduce this distinction to help discuss the merits specifically of Velleman's position.

11 Furthermore, in cases where the "belief" coheres with no evidence, as in certain delusions, it is also unclear to what extent it is right to conceive of it as a genuine belief. There is quite a literature on this very topic; see Egan (2009) for a useful gateway into it.

${ }^{12}$ Perhaps there is some level of aiming at the truth in between weak and strong that is strong enough to rule out imaginings but still weak enough to allow self-deceptive beliefs into the category of belief. I doubt a specification of such a level can be found, but I'd love to see an attempt.

${ }^{13}$ Recall especially the Wesiberg and Goodstein (2009) experiments, discussed in Part I, which very much help establish the idea that many imaginings have at least a weak truth aim.
} 
I'm in danger" (160-161). Hence, imagining satisfies Schema I too, so that schema doesn't distinguish belief from imagining. We could try adding other schemata with additional inference rules-Schema $I$ ' for conjunction elimination, Schema $I$ ' for contradiction elimination, etc. But imaginings—at least approximately—satisfy these too. ${ }^{14}$

So the inferential functions of imagining parallel those of belief to a large extent. Our problem remains.

Sinhababu continues:

But even here, there's material that helps us construct a distinction between believing and imagining.... While we might not be able to tell which mental states are beliefs and which are imaginings based on their inferential properties, their inferential properties differ in that they primarily produce states of their kind, and not the other. (p. 161)

Call this Sinhababu's No Inferential Mixing Thesis (SNIMT): although the inferential properties of imaginings and beliefs are parallel, the two classes of attitudes do not inferentially mix in the sense of one class's yielding attitudes of the other kind. This sounds like progress.

Unfortunately, SNIMT is false. That's because beliefs are used in inference from one imagining to others, as Part I argued. If I imagine putting corn on the lit barbecue, I'll imagine the corn getting hot, because I believe lit barbecues heat things. So beliefs aid inference from earlier to later imaginings, contrary to SNIMT. In addition to having been noted in Part I under the name Belief Governance Thesis, this fact has been referred to in the literature under various names, including the Reality Principle (Walton 1990, pp. 144 ff.) and the Mirroring Principle (Gendler 2003).

So "mixing" of some sort occurs. Is the inferentialist approach defeated? Not yet. Consider the other direction. If I believe that $p$ and merely imagine that $p \rightarrow q$, do I then believe that $q$ ? No! If I believe the cat is in the basement and imagine if the cat is in the basement, she can fly, I do not then believe she can fly. Rather, I merely imagine it, which shows that imaginings don't do inferentially for beliefs what beliefs do for imaginings. Similar examples can be adduced indefinitely. Suppose I believe I just pressed $R$ (as I just did) and imagine if I press $R$ a magic genie comes out (as I just imagined); I don't then believe (on pain of delusion) a magic genie comes out. So again the imagining does not supply the informational background to infer a new belief from a previous one.

Finally, a clear difference. There is an anti-symmetric relation among classes of cognitive attitudes. Beliefs partly constitute the informational background for inferences from imaginings to other imaginings, but not vice versa: imaginings don't do this for beliefs. ${ }^{15}$ To make this point rigorous, let's consider Schema AIB (for antisymmetric informational background):

\footnotetext{
${ }^{14}$ At least for imaginings within one single episode.

15 Gendler $(2003,2006)$ notes a number of apparent exceptions to this generalization, where imaginings behave cognitively at least somewhat as beliefs do, including in influencing beliefs in ways that it seems only beliefs and percepts should. She calls this cognitive contagion. But while
} 
Schema AIB: If one has CA___ 1 that $p \rightarrow q$ and CA___ 2 that $p$, and reflects properly on these propositions, then one will have $\mathrm{CA}_{ـ} \_$_ 2 that $q$.

We can now state the Inferential Anti-Symmetry Thesis (IAST): belief satisfies the $\mathrm{CA} \_$_ 1 place, when imagining is assigned the $\mathrm{CA} \_$_ 2 place, but not vice versa. ${ }^{16}$

In other words, if I believe that $p \rightarrow q$, imagine that $p$, and reflect properly, then I will imagine that $q$ (I won't believe that $q$ ). But if I imagine that $p \rightarrow q$ (without also believing it), believe that $p$, and reflect properly, then I will not believe that $q$ (I will imagine that $q$ ). So an inferential anti-symmetry exists.

Since Schema AIB doesn't presuppose either the notion of belief or imagining, IAST is an informative solution to our problem. Many related Schemata for different inference rules will be needed, but the general idea is clear. ${ }^{17}$ Further, this solution is consistent with the idea that imaginings have properties very similar to beliefs; imaginings behave inferentially largely as beliefs do, but they have a broader informational background for generating inferences: beliefs have other beliefs only, but imaginings have imaginings ${ }^{18}$ and beliefs. Sinhababu was close with SNIMT, but IAST is an inferentialist approach that actually appears to solve the problem. ${ }^{19}$

\section{The Big Picture: What Sort of Cognitive System is a Human?}

Let's take stock. We wanted to characterize the attitude of imagining and distinguish it from belief. Distinguishing them is difficult because imaginings, as

cognitive contagion exists, we must grant that if it were too widespread, the distinction between believing and imagining would disappear. So for any creature capable of having beliefs and imaginings at all, cognitive contagion must be seen as an exception to the cognitive rule, since the very notion of it only makes sense if imaginings and beliefs are by and large quarantined in the relevant ways.

${ }^{16}$ Anti-symmetry instead of asymmetry to allow reflexivity: the class of beliefs also inferentially governs itself, as does the class of imaginings.

${ }^{17}$ So we characterize the two attitudes by way of their contrast with one another. We are thus using the familiar Hilbertian strategy of implicit definition, which is the backbone of functionalist philosophy of mind.

18 Including genre truth attitudes; Part I, p. 228.

${ }^{19}$ IAST seems to me to be implied, or at least implied with few additional assumptions, by a pair of principles that Gendler (2003) puts forth as characteristic of cognitive systems that have imaginings and beliefs (even though the principles have exceptions): "The (prop-based) principle concerning quarantining specifies how what is pretended affects what is believed: it says that when one pretends that $X$ is $Y$, things that are believed to be true of $Y$ do not come to be believed to be true of $X$ merely because they are pretended to be true of X. The (prop-based) principle concerning mirroring specifies how what is believed affects what is pretended: it says that when we pretend $\mathrm{X}$ is $\mathrm{Y}, \mathrm{X}$ is-in the pretense-taken to have the effects and features that $Y$ is - in reality-believed to have."

Roughly, mirroring gives the claim of belief governance and quarantine the claim of anti-symmetry, on the reasonable assumption that "pretend" in the quotation is taken to apply the attitude of imagining we're discussing here. Gendler does not, however, put these principles forth as a solution to the problem we are addressing here (that of distinguishing belief from imagining), so in that respect, the way IAST is used here represents a step forward. 
"make-believe" implies, in so many ways resemble beliefs. ${ }^{20}$ But at least one relation between belief and imagining distinguishes them: inferential anti-symmetry.

A metaphor may help. An imaginer is a person walking a dog on a leash. The person (belief) is slower, sticking to the path. The dog (imagining) is quicker, tending to run around. The leash is belief's governance of imagining. When fewer beliefs are recruited in governing an episode of imagining, the leash has been let out further-imagining runs more freely. When more beliefs are recruited, the leash has been drawn in. Either way, the leash can never fully disappear, on pain of dissipation of the imaginative cognitive system as a whole. What the observation of similarities between beliefs and imaginings shows is that the walker and the dog are far more alike that we initially imagined.

\section{Imagining in Action}

We are finally in a position to ask our third question: how do imaginings impact behavior, especially pretending, and emotion? When you pretend to be a monkey who wants a banana, where "pretend" implies bodily behaviors (say, 'looking' for a banana in the bushes), you presumably have some attitude imaginings that underlie and support those behaviors. ${ }^{21}$ How do those imaginings guide your actions? How do they impact emotion? Here I discuss two views that have some currency.

\section{The Replacement Account: i-desires}

Beliefs and desires, on standard views, jointly cause and rationalize actions that make the contents of desires true, if the beliefs are true. The i-desire theorist says the structure of pretense causation is similar, except with imaginings and idesires (an imaginative substitute for desires) instead of beliefs and desires. If you idesire a banana and imagine you might find one in the bush, you'll go to the bush and 'look' for a banana. That is how you pretend to look for a banana. So to be clear, i-desires are meant as a new posit in psychological ontology, one that has the virtue of helping to explain pretense and other aspects of fictional engagement. ${ }^{22}$

This view seems plausible in virtue of nicely paralleling standard views of plain action. Furthermore, the positing of i-desires seems to offer an account of how fictions excite emotional states. As Doggett and Egan (2012) write in discussing the anxiety they felt at the end of Romeo and Juliet:

\footnotetext{
20 But see Walton (1990: ch. 4).

21 Most, but not all, agree. See Leslie (1987, 1994) and Langland-Hassan (2012) for differing views. Leslie tries to explain pretense by positing the concept of PRETEND in the mind of the pretender (without attitude imaginings in the sense relevant here). Langland-Hassan tries to explain pretense by way of conditional beliefs (without imaginings). Langland-Hassan is very much inspired by Nichols and Stich (2003), who also attempt to use conditional beliefs (with imaginings) to explain pretense. For reasons of space, I cannot discuss conditional belief accounts here, though see Doggett and Egan (2007), Friedman and Leslie (2007), and my (2011) for critiques of the Nichols and Stich presentation of it, which in my view apply to the Langland-Hassan presentation of it as well. 22 When Velleman, quoted above, writes about "various desires with respect to my fictional world," he has in mind what others call i-desires.
} 
We propose, again, that the origin of our anxious affect had a cognitive and a conative component. But the cognitive component wasn't a belief-it was an imagining, a cognitive state analogous to a belief. And the conative component wasn't a desire-it was a conative state that stands to desire as imagining stands to belief, an i-desire. (p. 278)

Their idea is that the combination of imagining that $p$ and i-desiring $\sim p$ generates negative affect similar to the affective state consequent on believing that $p$ and desiring that $\sim p$; imagining that $p$ while i-desiring that $p$ generates some positive emotional state.

The i-desire posit has a number of other arguments in favor of it. I'll just mention the main one to which Doggett and Egan appeal: it helps explain the possibility that we are not conflicted when we want (i-desire) certain things for the characters in a story without wanting (desiring) the story to be other than it is. I $i$ desire Romeo and Juliet to live happily, for example, but I desire that Shakespeare's story not change at all. Doggett and Egan argue that if the first conative state were a real desire, it would somehow undermine the second desire. But it doesn't, so it must be something else: i-desire seems to fit the bill.

Should i-desires declare victory? Not yet. The pressure to posit i-desires distinct from desires is weaker than the pressure to posit imaginings distinct from beliefs. Amy Kind (2011) points out it is common to have real desires about things we believe don't exist. I desire that my children, who I know don't exist yet, be generous and happy. Desires are often patient, hopeful mental states, that come into existence long before (or after) the objects they are about. So it's plausible that we have genuine desires about characters we know are only fiction, real desires not about the fiction but about the characters themselves.

Here's a way of seeing the point.

How do you tell the difference between someone who imagines Harry Potter is fighting Voldemort and someone who believes this? That's easy. The second one acts crazy, sincerely informing people of the epic upcoming fight and attempting to call the Ministry of Magic to tell them about it. The first, the imaginer, just gets really into the story and maybe acts it out in the practical setting of make-believe, but she doesn't act confused about reality. Thus, a large behavioral difference is explained by a clear underlying difference in cognitive attitudes, imagining versus belief.

But how do you tell the difference between someone who desires that Harry win the fight and someone who i-desires that Harry win the fight? That is, how do you tell the difference between someone with (a) and someone with (b), other things being equal?

(a) $\mathrm{D}_{\mathrm{k}}$ Harry wins the fight.

(b) i- $\mathrm{D}_{\mathrm{k}}$ Harry wins the fight

The person with (a), assuming her beliefs are rational, will probably not act any crazier than the person with (b). In fact, it's not obvious that the person with (a) will act differently at all from the person with (b). So one starts to suspect that (a) and 
(b) aren't really different. What really is the difference? Doggett and Egan would hold [first] that (a) will always lead to desires about the fiction, which would lead to conflicting desires about the fiction (which they say we don't have). They then stipulate [second] that (b) won't lead to any desires about the fiction. But the first point is doubtful and the second is stipulative. So we could spare ourselves the stipulative posit of i-desires by denying the doubtful first point. The argument in favor of i-desires-that they help explain the absence of conflict-seems tenuous.

I don't think i-desires are out of the running for explaining pretending and emotions in response to fiction. But the case so far is problematic enough that one might, with Kind, wield the swift sword of parsimony against them. But I do think Doggett and Egan have made it apparent that we have desires of some sort about fictional entities; these desires partly explain our emotions in response to imagining. Whether these desires are a distinct species is unsettled. It is worth, in any case, trying to see how much we can explain without them. ${ }^{23}$

\section{Direct Influence: Mental Imagery, Pragmatic Mental Imagery, and Scripts}

The next family of views, accordingly, has a simpler psychological ontology. It includes work by Eric Funkhouser and Shannon Spaulding (2009), Bence Nanay (2014), myself (2011, forthcoming), and-in relation to emotions-Timothy Schroeder and Carl Matheson (2006). The shared idea is this: imaginative representations structure or "guide" pretense and other actions directly, without needing i-desires to motivate or various forms of belief ${ }^{24}$ in between the imagining and the action. The related idea is that imaginings spark emotional responses directly. I call this family of ideas The Direct Approach, since it portrays at least a broad class of pretense actions as having their structure encoded in the imaginative representations that cause them, without positing a process like practical reasoning to get from the imagining (and corresponding i-desire) to the action.

Let's return to our earlier example. You pretend to be a monkey looking for a banana; now you pretend to find it. You jump up and down in excitement, pounding your chest and screaming.

The i-desire theorist, I think, has trouble with such an example. What do you, in your role as monkey, i-desire such that you jump up and down on finding the banana? Do you i-desire to express your joy at finding the banana and imagine that such movements express joy? This would make the psychological processes that produce the pretense analogous to ordinary belief-desire practical reasoning. But if Rosalind Hursthouse (1991) is right, this explanation form is suspect even for nonpretense expressive actions, like jumping for joy. I think it is at least as suspect for pretended expressive actions.

The Direct Approach, on my version, suggests this. You have representations in your mind - mental imagery - of how monkeys behave when they find bananas. You visualize (imagistic imagining) a monkey jumping up and down and screaming.

\footnotetext{
${ }^{23}$ I unfortunately don't have space here to address Gregory Currie's (2010) interesting argument in favor of i-desires. I recommend that piece to the reader. Shen-yi Liao and Tyler Doggett (forthcoming) also have a defense of positing i-desires that is well worth considering.

${ }^{24}$ Like conditional beliefs (see fn. 21).
} 
Then imitating what you visualize, you jump up and down and scream. Just as you could pretend to be a monkey by imitating a monkey you actually see, you can also pretend to be a monkey by imitating the monkey that you imagistically imagine. Imagery substitutes for percepts in saturating the object-imitated role. This explanation does without the i-desire theorist's imaginative practical reasoning, which, at least for this case, seems an improvement.

Nanay $(2013$, ch. 5) holds a closely related view, but his broader class of pragmatic mental imagery more explicitly includes unconscious imagery. ${ }^{25}$ Pragmatic mental imagery represents the action-guiding properties of an object of pretense. For example, when you are pretending to bring an imaginary cup to your lips, you may not have a conscious visualization of the cup in your hand, but you do have a representation that is spatially rich, as is perception and imagery, that represents the size of the cup such that you hold your hand around it in the position you do. As Nanay puts it:

\begin{abstract}
When I am pretending to raise my glass with nothing in my hands ... I also need to have pragmatic mental imagery that allows me to hold my fingers and move my hand in a certain way. This pragmatic mental imagery attributes action properties (weight, shape and spatial location properties) to the imagined glass in my hand. (pp. 117-118)
\end{abstract}

The idea is that, at least once the pretense action is initiated, the pragmatic mental imagery of the cup guides the bodily movement and hand position directly, without any sort of reasoning needing to be done about the particular shape of one's hand position.

Funkhouser and Spaulding emphasize yet a broader category of imaginative representations that structure pretending. They introduce the notion of a script, analogous to the script of a play.

A script, unlike the typical belief used in means-end reasoning, is something that can be imitated or enacted. Significantly, these scripts can sometimes guide action without being mediated by a belief or knowledge state. We claim that imagination, in its role of guiding pretense, can be one such script. (p. 309)

The mental imagery just discussed would be one kind of script, but there are other kinds too, such as a general representation of the sequence of events when one buys a garment at a store (their running example). There may not be specifically visualized bodily movements when one pretends to ask for the store manager, but there is still a script that orders the sequence. Scripts for them can either be external or internal, and, as a type of "guider," they can, jointly with "motivators," cause and rationalize action. The key point, however, which puts this view in the Direct Approach family, is that scripts can be "imitated or enacted," which means that once script-based action is initiated, the imaginings guide actions in a direct way. ${ }^{26}$

\footnotetext{
${ }^{25}$ In my (2011, fn. 4), I also include unconscious imagery. But it's fair to say don't emphasize it nearly so much as Nanay does.

${ }^{26}$ I've argued for a similar position (2009), extending Bratman's (1992) notion of acceptance in a context to the realm of make-believe.
} 
A natural ally of these views of pretense is a direct view of how imaginings impact emotions. When you imagine Juliet taking the poison, you feel heartache. Must you really have an i-desire that she not drink the poison in order to feel this? Or is it enough to have followed along with the story (if you're reading) and vividly visualize her weeping eyes as she tilts her head back? Two points are important in supporting this view, both of which Schroeder and Matheson (2006) emphasize, as do I (2011, forthcoming). First, as Part I emphasized, imagistic imaginings play out on the perceptual cortices of the brain: the cortices that process vision process visual imagery too; auditory cortices process auditory imagery; and so on. Second, there are-for ecological reasons-fast and direct connections (no mediating beliefs) from perceptual cortices to areas of the brain that process emotions. So the Direct Approach to imagination and emotion says this: however it is that percepts impact emotions, that's how imagistic imaginings do it. And since imagistic imaginings are often constituents of attitude imaginings, the Direct Approach holds that they are important to explaining how attitude imaginings themselves spark emotion, and hence important to explaining emotional responses to fiction. ${ }^{27}$

\section{Conclusion: Extending the Image}

Return to the imagined purple-eyed dragon. What is it for the dragon representations in your mind to be fictional imaginings, as opposed to beliefs? The answer at least in part lies in an anti-symmetric inferential relation that exists between the class of beliefs and the class of imaginings. If you imagine the dragon flying into the side of a mountain, your beliefs about physical objects in part govern what you imagine next. But when you believe that a plane crashed into the side of the mountain, your other beliefs about the physical world, not your imaginings, govern what you infer. ${ }^{28}$ So anti-symmetric inferential governance allows us to identify two classes of cognitive attitudes, one of which is belief and the other of which is imagining.

It's marvelous that we have this second class. Since imaginings are, as Tamar Gendler (2003) puts it, mostly quarantined from belief -in virtue, I think, of the identified anti-symmetry-we can play with them as we like and even allow them to guide action directly, without fearing the epistemic degradation that would come from having outlandish representations injected into the class of beliefs. ${ }^{29}$ If this is right, then pretend play is a bodily extension of attitude imagining that allows the external world to govern the pretense behavior-shaping it, limiting it, giving it implications - in the way that, internally, beliefs govern imaginings. Pretending is putting imagining in the world.

\footnotetext{
${ }^{27}$ I should note for the sake of clarity that the Direct Approach and the Replacement Account do not strictly speaking conflict: it could be the case that both sorts of process are at work at different times. Nevertheless, since the two accounts give differing explanations of many of the same phenomena, it is fair to see them as competitors.

28 This claim sets aside cases of things like pathological beliefs and false memories, and in so doing it assumes a competence / performance distinction in the functioning of belief and imagining. I won't argue for this distinction here, except to say that a large range of human abilities can be explained, if we assume it, that are obscure without it.

29 There is, of course, risk of "contagion," but contagion isn't always bad. And the risk seems worth it.
} 


\section{Acknowledgements}

I'd like to thank Bence Nanay, Shannon Spaulding, and one anonymous referee for helpful comments on earlier drafts of this paper. I also thank Michelle Montague for giving helpful feedback on how to structure the piece.

\section{References}

Bratman, M. E. (1992) “Practical Reasoning and Acceptance in a Context," Mind 101, pp. $1-15$.

Currie, G., and I. Ravenscroft (2002) Recreative Minds: Imagination in Philosophy and Psychology, Oxford: Oxford University Press.

Currie, G. (2010) “Tragedy," Analysis 70: 1-7

Doggett, T., and A. Egan (2007) “Wanting Things You Don't Want: the Case for an Imaginative Analogue of Desires," Philosopher's Imprint 9:01/17/13

Doggett, T., and A. Egan (2012) "How we feel about Terrible, Non-Existent Mafiosi," Philosophy and Phenomenological Research 84 (2): 277-306.

Egan, A. (2009) "Imagination, Delusion, and Self-Deception," In Delusions, SelfDeception, and Affective Influences on Belief-Formation, Tim Bayne and Jordi Fernandez, eds., Psychology Press.

Friedman, O. and Leslie, A. M. (2007) "The conceptual underpinnings of pretense: Pretending is not 'behaving as if'," Cognition 105: 103-124.

Funkhouser, E. and Spaulding, S. (2009) "Imagination and Other Scripts," Philosophical Studies 143(3): 291-314.

Gendler, T. S. (2003) "On the Relation between Pretense and Belief," in Imagination, Philosophy and the Arts, eds. D. M. Lopes and M. Kieran, Routledge, London: $125-141$.

Gendler, T. S. (2006) "Imaginative Contagion," Metaphilosophy 37(2): 183-203.

Hume, D. (1777/1993) An Enquiry Concerning Human Understanding, ed. E.Steinberg, Indianapolis/Cambridge: Hackett Publishing Company.

Hursthouse, R. (1991) “Arational Actions," Journal of Philosophy 88(2): 57-68.

Kind, A. (2011) "The Puzzle of Imaginative Desire," Australasian Journal of Philosophy 89(3): 421-439.

Langland-Hassan, P. (2012) "Pretense, Imagination, and Belief: the Single Attitude Theory," Philosophical Studies 159: 155-179.

Leslie, A. M. (1987) "Pretense and representation: The origins of 'theory of mind,"” Psychological Review 94: 412-426.

Leslie, A. M. (1994) "Pretending and believing: Issues in the theory of ToMM," Cognition 50: 211-238.

McGinn, C. (2004) Mindsight, Cambridge, Harvard University Press.

Nanay, B. (2013) Between Perception and Action, Oxford: Oxford University Press.

Nichols, S. and Stich, S. (2003) Mindreading: An Integrated Account of Pretence, SelfAwareness, and Understanding Other Minds, Oxford: Oxford University Press. O'Shaughnessy, B. (2000) Consciousness and the World, Oxford: Clarendon Press. Schellenberg, S. (forthcoming) "Belief and Desire in Imagination and Immersion," Journal of Philosophy. 
Shah, N., and J. D. Velleman (2005) “Doxastic Deliberation," Philosophical Review 114(4): 497-534.

Schroeder, T. and Matheson, C. (2006) "Imagination and Emotion," in S. Nichols (ed.), The Architecture of Imagination, New York, Oxford University Press.

Sinhababu, N. (2013) "Distinguishing Belief and Imagination," Pacific Philosophical Quarterly 94(2): 152-165.

Stroud, B. (1981) Hume, New York: Routledge.

Van Leeuwen, N. (2009) "The Motivational Role of Belief," Philosophical Papers 38(2), 219-246.

Van Leeuwen, N. (2011) "Imagination is Where the Action Is," Journal of Philosophy 108(2), 55-77.

Van Leeuwen, N. (2013) “The Meanings of 'Imagine' Part I: Constructive Imagination," Philosophy Compass 8(3), 220-230.

Van Leeuwen, N. (forthcoming) "The Imaginative Agent," in Knowledge Through Imagination eds. Amy Kind and Peter Kung, Oxford, Oxford University Press.

Velleman, J. D. (2000) The Possibility of Practical Reason, Oxford, Oxford University Press.

Velleman, J. D. (2000a) “On the Aim of Belief," in The Possibility of Practical Reason: 244-281.

Walton, K. (1990) Mimesis as Make-Believe, Cambridge, Harvard University Press.

Weisberg, D. S. and Goodstein, J. (2009) "What belongs in a fictional world?" Journal of Cognition and Culture, 9, 69-78. 